CLINICAL STUDY

\title{
IGF 1 and its binding proteins 3 and 1 are differentially associated with metabolic syndrome in older men
}

\author{
Bu B Yeap ${ }^{1,2}$, S A Paul Chubb ${ }^{1,3}$, Ken K Y Ho ${ }^{4}$, Johnson W S Setoh ${ }^{3}$, Kieran A McCaul ${ }^{5}$, Paul E Norman ${ }^{6}$, \\ Konrad Jamrozik ${ }^{7}$ and Leon Flicker ${ }^{1,5}$ \\ ${ }^{1}$ School of Medicine and Pharmacology, University of Western Australia, Perth, Western Australia 6009, Australia, ${ }^{2}$ Department of Endocrinology and \\ Diabetes and ${ }^{3}$ PathWest Laboratory Medicine, Fremantle Hospital, Fremantle, Western Australia 6160, Australia, ${ }^{4}$ Pituitary Research Unit, Garvan \\ Institute of Medical Research, Sydney, New South Wales 2010, Australia, ${ }^{5}$ WA Centre for Health and Ageing, Centre for Medical Research and ${ }^{6}$ School of \\ Surgery, University of Western Australia, Perth, Western Australia 6009, Australia and ${ }^{7}$ School of Population Health and Clinical Practice, University of \\ Adelaide, Adelaide, South Australia 5000, Australia
}

(Correspondence should be addressed to B B Yeap at School of Medicine and Pharmacology, Level 2, T Block, Fremantle Hospital, Alma Street, Fremantle, Western Australia 6160, Australia; Email: byeap@cyllene.uwa.edu.au)

\begin{abstract}
Objective: Circulating IGF1 declines with age, and reduced circulating IGF1 is associated with increased cardiovascular mortality in some but not all studies. The relationship between IGF-binding proteins 3 and 1 (IGFBP3 and IGFBP1) with risk of cardiovascular disease remains unclear. We sought to examine associations between IGF1, IGFBP3 and IGFBP1 with metabolic syndrome in older men.

Design: Cross-sectional analysis of 3980 community-dwelling men aged $\geq 70$ years.

Methods: Morning plasma levels of IGF1, IGFBP3 and IGFBP1 were assayed. Metabolic syndrome was defined according to National Cholesterol Education Program-Adult Treatment Panel III (NCEP-ATPIII) criteria.

Results: For IGF1 and IGFBP3, there was a U-shaped relationship, with middle quintiles possessing the lowest odds ratios (OR) for metabolic syndrome (reference Q1, Q3 IGF1: OR 0.74, 95\% confidence intervals 0.57-0.96, Q3 IGFBP3: OR 0.67, 0.51-0.87). Increasing IGFBP1 was associated with reduced risk of metabolic syndrome with a dose-response gradient (reference Q1, OR for Q2 to Q5 IGFBP1: 0.56, $0.33,0.22$ and 0.12 respectively, $P<0.001$ ). IGF1 was associated with two, IGFBP1 with four and IGFBP3 with all five components of the metabolic syndrome. The ratio of IGF1/IGFBP3 was not associated with metabolic syndrome.

Conclusions: In older men, both lower and higher IGF1 and IGFBP3 levels may be metabolically unfavourable. IGFBP1, as a marker of insulin sensitivity, is relevant in the assessment of metabolic syndrome, while the IGF1/IGFBP3 ratio is less informative. Longitudinal follow-up of this cohort would be needed to determine whether these distributions of IGF1, IGFBP3 and IGFBP1 predict incidence of cardiovascular events during male ageing.
\end{abstract}

European Journal of Endocrinology 162 249-257

\section{Introduction}

Ageing is associated with gradual erosion of health and well-being, and by declining pituitary GH secretion resulting in a reduction in circulating insulin-like growth factor 1 (IGF1) (1). Adults who are GH deficient are at risk of metabolic syndrome, and GH replacement therapy raised IGF1 levels, improved body composition and markers of cardiovascular risk (2-4). In older men who do not have pituitary disease, lower IGF1 has been associated with unfavourable lipid profiles, with occurrence of ischaemic heart disease and stroke (5-8), and with cardiovascular mortality $(9,10)$. By contrast, other studies have been inconclusive, or have associated higher IGF1 with increased cardiovascular risk or mortality (11-15). In normal men, there is a lack of clinical trial data supporting beneficial outcomes of
GH supplementation. Thus, whether lower IGF1 levels are a treatable risk factor for cardiovascular disease in ageing men remains topical and controversial. It is possible that in the elderly, reduced GH secretion resulting in lower IGF1 levels may be a marker for cardiovascular risk rather than a cause of cardiovascular disease, or a secondary phenomenon in the presence of increasing age and adiposity. Therefore, the relationship between IGF1 and risk of cardiovascular disease merits further exploration.

IGF 1 interacts in the circulation with several IGF-binding proteins (IGFBPs), which regulate its binding to cellular IGF1 receptors (16). The majority of IGF1 circulates bound with high affinity to a complex containing IGFBP3, and IGFBP1 further modulates bioavailability of IGF1 (17). Higher IGFBP3 levels, which would be expected to reduce unbound or 
bioavailable IGF1, have been observed to be correlated with cardiovascular risk or disease in a number of studies $(6,7,12,13)$. However, other studies have reported contrary results with lower IGFBP 3 associated with increased risk of coronary events, stroke or mortality $(8,10,11)$. IGFBP 3 does interact with several cell signalling pathways (17); therefore, it possibly could modulate cardiovascular risk independent of IGF1. A reduced ratio of IGF1/IGFBP3 has been proposed as a marker of metabolic syndrome (18), but the clinical utility of this ratio has not been confirmed. Reduced IGFBP1 has been identified as a marker of insulin resistance and the presence of metabolic syndrome $(19,20)$. Lower IGFBP1 has been associated with increased mortality from ischaemic heart disease and with greater carotid intima-media thickness in the setting of type 2 diabetes $(9,21)$. Additional investigation of the associations between these IGFBPs and cardiovascular risk would be informative, particularly in the population of ageing men.

Clarifying associations of circulating IGF1 and its binding proteins with cardiovascular risk would help to establish whether these markers are of value in identifying older men at risk of ill-health. This would be a necessary prerequisite to designing effective intervention studies to examine the effects of either lifestyle modification or pharmacological treatment to prevent disease in older persons found to have low IGF1 levels. Therefore, we tested the hypothesis that reduced levels of IGF1 and its binding proteins are associated with metabolic syndrome in a population-based cohort of older men.

\section{Subjects and methods}

\section{Study population}

Details of the Health In Men Study (HIMS) have been described in depth elsewhere (22). Briefly, between October 2001 and August 2004, a population-based sample of 4263 community-dwelling men resident in metropolitan Perth, Western Australia, participated in the study. Men were predominantly of Caucasian ethnicity. Demographic, medical and medications data were collected. Height (in centimetres), weight (in kilograms), waist and hip circumference (in centimetres) and blood pressure were measured using standard procedures. An early morning blood sample was collected for analysis of biochemistry and hormone levels. The Human Research Ethics Committee of the University of Western Australia approved the study protocol, and all study participants gave their written informed consent.

\section{Assessment of medical comorbidity}

We used the Charlson score (23) to determine the presence of significant medical comorbidity in our cohort. The score takes into account 17 common medical conditions that predict 1-year mortality: myocardial infarction, congestive heart failure, peripheral arterial disease, cerebrovascular disease, dementia, chronic pulmonary disease, connective tissue disease, ulcer disease, liver disease, diabetes (including diabetes with end-organ damage), hemiplegia, renal disease, leukaemia, lymphoma, other tumours, metastatic tumours and AIDS. Medical diagnoses are weighted for severity and summed to provide a weighted index of medical comorbidity. Data were included from 1990 to the time of blood sampling, providing a measure of recent comorbidity.

\section{Definition of metabolic syndrome}

Metabolic syndrome was defined according to the National Cholesterol Education Program-Adult Treatment Panel III (NCEP-ATPIII) classification as three or more of: waist circumference $>102 \mathrm{~cm}$, fasting plasma glucose $\geq 5.6 \mathrm{mmol} / \mathrm{l}$ or a known diagnosis of diabetes, fasting serum triglycerides $\geq 1.7 \mathrm{mmol} / \mathrm{l}$, fasting highdensity lipoprotein (HDL) cholesterol $<1.03 \mathrm{mmol} / \mathrm{l}$ or blood pressure $\geq 130 / 85 \mathrm{mmHg}$. We used the recent modification of the definition, which lowered the threshold for an abnormal glucose concentration to $\geq 5.6 \mathrm{nmol} / \mathrm{l}$ (24). Men with a previous diagnosis of hypertension or taking anti-hypertensive therapy were regarded as fulfilling the criteria for hypertension.

\section{Laboratory assays}

Blood samples were collected between 0800 and $1030 \mathrm{~h}$. Plasma was prepared immediately following phlebotomy and stored at $-80{ }^{\circ} \mathrm{C}$ until assayed. Biochemical and hormone assays were performed in the Biochemistry Department, PathWest Laboratory Medicine, Fremantle and Royal Perth Hospitals, Western Australia. IGF1, IGFBP1 and IGFBP3 were assayed using reagent kits of single lot numbers from Diagnostics Systems Laboratories Inc. (DSL, supplied by Beckman Coulter, Gladesville, NSW, Australia). The non-extraction IGF1 ELISA, the total IGFBP1 ELISA and the active IGFBP3 ELISA kits were used. The assays were automated using a Grifols Triturus ELISA processor (Vital Diagnostics, Castle Hill, NSW, Australia). Between-run imprecision (coefficient of variation) was 12.2 and $8.6 \%$ at 117 and $216 \mu \mathrm{g} / \mathrm{l} \mathrm{IGF1,} 8.6$ and $5.2 \%$ at 3.1 and $49 \mu \mathrm{g} / \mathrm{l}$ IGFBP1, and 16.8 and $4.4 \%$ at 540 and $4300 \mu \mathrm{g} / \mathrm{l} \mathrm{IGFBP3}$. All assays were carried out on freshly thawed aliquots of EDTA plasma. In preliminary testing, EDTA plasma gave results that were $<5 \%$ different from those for serum in the IGF1, IGFBP1 and IGFBP3 assays. Fasting serum glucose, total and HDL cholesterol, and triglycerides were estimated using a Roche Hitachi 917 analyser (Roche Diagnostic $\mathrm{GmbH}$ ). Between-day imprecision for glucose was $2.9 \%$ at $4.8 \mathrm{mmol} / \mathrm{l}$ and $2.2 \%$ at $15.2 \mathrm{mmol} / \mathrm{l}$, for cholesterol it was $2.3 \%$ at $3.2 \mathrm{mmol} / \mathrm{l}$ and $2.1 \%$ at $6.7 \mathrm{mmol} / \mathrm{l}$, for HDL it was $2.4 \%$ at $0.8 \mathrm{mmol} / \mathrm{l}$ and $2.5 \%$ at $1.7 \mathrm{mmol} / \mathrm{l}$, and for triglycerides it was $4.8 \%$ at $0.9 \mathrm{mmol} / \mathrm{l}$ and $2.4 \%$ at $2.0 \mathrm{mmol} / \mathrm{l}$. 


\section{Statistical analysis}

Data were analysed with the statistical package Stata, version 10.0 (StataCorp, College Station, Texas, USA, 2007). Distributions of IGF1, IGFBP3 and IGFBP1 in men with and without metabolic syndrome were compared. Data are tabulated as mean \pm s.D. or s.E.M. Mean comparisons were performed using Student's t-test. Logistic regression analysis was used to assess odds ratio (OR) for metabolic syndrome across quintiles of IGF1, IGFBP 3 and IGFBP1 adjusting for age, smoking and alcohol use. Associations of IGF1, IGFBP3 and IGFBP1 with individual components of the metabolic syndrome were examined. $P$ values of $<0.05$ were considered significant.

\section{Results}

\section{IGF1, IGFBP3 and IGFBP1 levels in community-dwelling older men}

After excluding men for whom suitable plasma aliquots could not be retrieved and men with incomplete data, there were 3980 men included in the analysis. Distributions of plasma IGF1, IGFBP3, IGFBP1 and $\ln ($ IGFBP1) are shown in Fig. 1 (A-D respectively). Plasma IGF1 was strongly correlated with IGFBP3 level $(r=0.59, P<0.001)$. There were weaker inverse correlations between IGF1 and $\ln (\mathrm{IGFBP} 1)$ and between IGFBP 3 and $\ln (\mathrm{IGFBP} 1)(r=-0.16$ and $r=-0.11$ respectively, both $P<0.001)$.

\section{Associations of age, body mass index and medical comorbidity with IGF1, IGFBP3 and IGFBPI levels}

There were 105 men who had an admission to hospital for cancer in the year prior to participation in HIMS, and in nine of these it was metastatic. The proportion of men who reported a history of diabetes was $13.9 \%$. Both malignancy and diabetes are components of the Charlson weighted index of medical comorbidity. The proportion of men with one or more defined comorbidities was 31\%. Univariate analyses of the associations between age, body mass index (BMI) and medical comorbidity (Charlson score) with each of IGF1, IGFBP3 and IGFBP1 are shown in Table 1. IGF1 and IGFBP3 levels decreased with increasing age, while IGFBP1 levels increased. IGF1 levels were lowest in men with BMI $<18.5 \mathrm{~kg} / \mathrm{m}^{2}$. IGFBP1 levels decreased with increasing BMI.

\section{Stratification of men according to absence or presence of metabolic syndrome}

For the assessment of metabolic syndrome, men who did not have fasting lipid profiles were excluded, leaving a total of 3241 men for this analysis. Of these, 935 had metabolic syndrome $(28.8 \%)$. Characteristics of the men according to whether or not metabolic syndrome was present are shown in Table 2. Men with metabolic syndrome had higher IGF1 and lower IGFBP1 levels than men without (144.4 vs $139.7 \mu \mathrm{g} / \mathrm{l}, P=0.04$ and 22.2 vs $32.3 \mu \mathrm{g} / \mathrm{l}, \mathrm{P}<0.001$ respectively). Neither IGFBP 3 levels nor the ratio of IGF1/IGFBP3 differed significantly between men without and with metabolic syndrome.
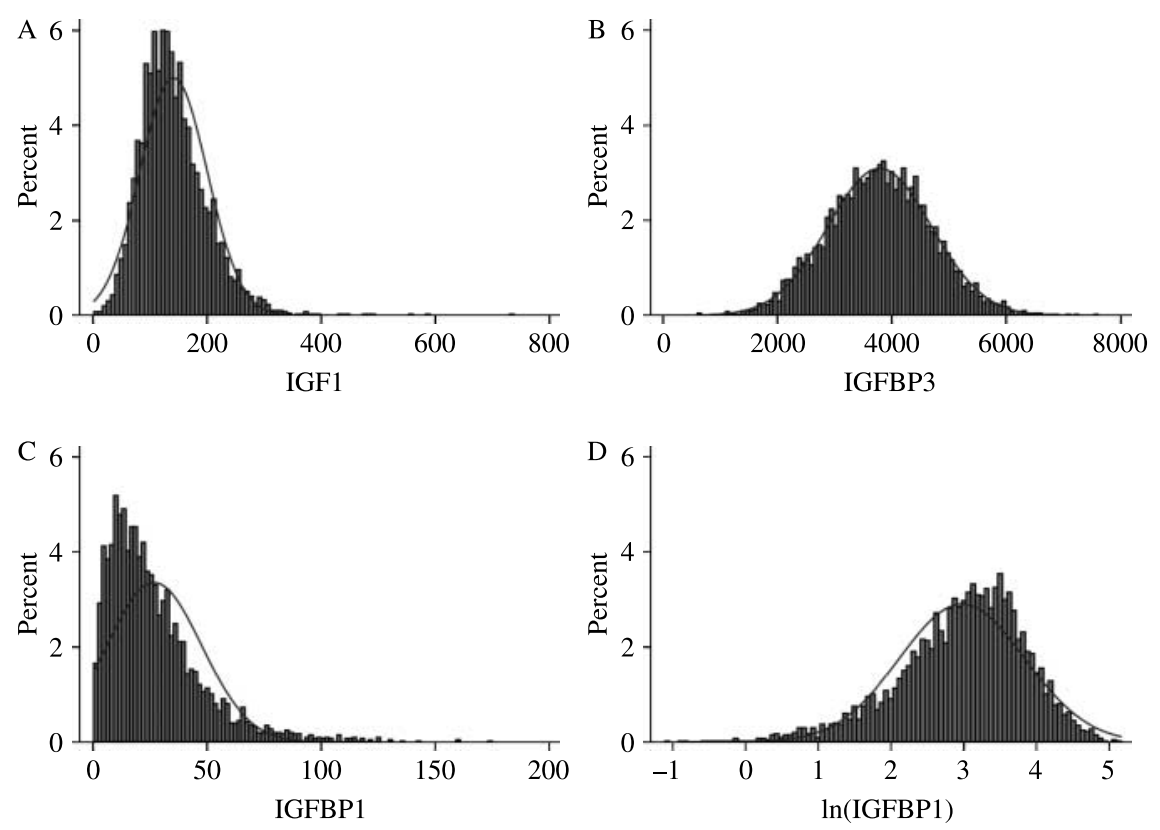

Figure 1 Distributions of IGF1 IGFBP3 and IGFBP1 in older men. Distributions of plasma IGF1 (A), IGFBP3 (B), IGFBP1 (C) and In(IGFBP1) (D) in 3980 communitydwelling older men. Units for IGF1, IGFBP3 and IGFBP1 are $\mu \mathrm{g} / \mathrm{l}$. Continuous lines are fitted curves showing how closely the data approximate parametric (normal) distributions. 
Table 1 Associations of age, body mass index (BMI) and medical comorbidity (Charlson score) with plasma insulin-like growth factor 1 (IGF1), IGF-binding proteins 3 and 1 (IGFBP3 and IGFBP1) levels in community-dwelling men aged $\geq 70$ years (univariate regression).

\begin{tabular}{|c|c|c|c|c|c|c|c|}
\hline \multirow[b]{2}{*}{ Covariate } & & \multicolumn{2}{|c|}{ IGF1 ( $\mu \mathrm{g} / \mathrm{l})$} & \multicolumn{2}{|c|}{ IGFBP3 ( $\mu \mathrm{g} / \mathrm{l})$} & \multicolumn{2}{|c|}{ IGFBP1 $(\mu \mathrm{g} / \mathrm{l})$} \\
\hline & & Mean $(95 \% \mathrm{Cl})$ & $P$ value & Mean $(95 \% \mathrm{Cl})$ & $P$ value & Mean $(95 \% \mathrm{Cl})$ & $P$ value \\
\hline Age (years) & $\begin{array}{l}70-74 \\
75-79 \\
80-84 \\
85-89\end{array}$ & $\begin{array}{l}148.8(145.7-151.9) \\
138.7(135.9-141.5) \\
134.4(130.2-138.6) \\
128.5(119.6-137.4)\end{array}$ & $<0.001$ & $\begin{array}{l}3940(3894-3985) \\
3778(3736-3820) \\
3523(3452-3593) \\
3443(3290-3596)\end{array}$ & $<0.001$ & $\begin{array}{l}23.2(22.3-24.2) \\
27.3(26.3-28.3) \\
31.6(29.8-33.3) \\
37.6(33.0-42.2)\end{array}$ & $<0.001$ \\
\hline BMI $\left(\mathrm{kg} / \mathrm{m}^{2}\right)$ & $\begin{array}{l}<18.5 \\
18.5-24.9 \\
25-29.9 \\
\geq 30\end{array}$ & $\begin{array}{l}122.8(103.3-142.2) \\
138.7(135.6-141.8) \\
144.0(141.4-146.6) \\
139.1(134.4-143.7)\end{array}$ & 0.026 & $\begin{array}{l}3603(3238-3968) \\
3781(3733-3830) \\
3815(3776-3853) \\
3716(3640-3792)\end{array}$ & 0.079 & $\begin{array}{l}72.6(58.1-87.1) \\
36.3(35.0-37.6) \\
23.7(22.9-24.4) \\
17.5(16.2-18.8)\end{array}$ & $<0.001$ \\
\hline Charlson score & $\begin{array}{l}0 \\
1 \\
2 \\
3 \\
4 \\
5+\end{array}$ & $\begin{array}{l}139.0(136.8-141.1) \\
141.7(136.2-147.1) \\
148.5(142.1-154.9) \\
153.9(144.1-163.7) \\
148.5(135.4-161.6) \\
151.5(139.2-163.8)\end{array}$ & $<0.001$ & $\begin{array}{l}3799(3766-3832) \\
3716(3631-3800) \\
3864(3770-3958) \\
3690(3547-3833) \\
3706(3486-3926) \\
3711(3532-3890)\end{array}$ & 0.084 & $\begin{array}{l}25.4(24.7-26.1) \\
28.1(26.1-30.0) \\
29.3(27.1-31.5) \\
29.4(26.2-32.6) \\
33.9(27.4-40.5) \\
38.4(32.2-44.6)\end{array}$ & $<0.001$ \\
\hline
\end{tabular}

\section{IGF1, IGFBP1 and IGFBP3 as predictors of metabolic syndrome in older men}

Results of the logistic regression analysis of metabolic syndrome on IGF1, IGFBP3, IGFBP1 and the ratio of IGF1/IGFBP3 are shown in Fig. 2, incorporating adjustment for age, smoking and alcohol use. For IGF1 and IGFBP3, there was a U-shaped relationship, with middle quintiles possessing the lowest ORs for metabolic syndrome. With the lowest quintile (Q1) as the reference group, men with IGF1 in Q3 had OR for metabolic syndrome of 0.74 (95\% confidence intervals (CI) $0.57-0.96, P=0.025)$. There was a significant trend across quintiles of IGF1 (overall significance $P=0.042$ ). Compared to men with IGFBP3 in Q1, men with IGFBP3 in Q2 had OR for metabolic syndrome of $0.64(95 \%$ CI $0.50-0.83, P=0.001) ; Q 3,0.67$ $(0.51-0.87, P=0.002)$, and $Q 4,0.63(0.48-0.82$, $P=0.001)$. There was a significant trend across

Table 2 Characteristics of older men stratified for the absence and presence of metabolic syndrome. Data shown are mean (S.D).

\begin{tabular}{lccr}
\hline & $\begin{array}{c}\text { No metabolic } \\
\text { syndrome } \\
n=2306\end{array}$ & $\begin{array}{c}\text { Metabolic } \\
\text { syndrome } \\
n=935\end{array}$ & $\boldsymbol{P}$ value \\
\hline Age (years) & $77.1(3.7)$ & $76.9(3.4)$ & 0.054 \\
BMl (kg/m $\left.{ }^{2}\right)$ & $25.4(3.0)$ & $29.0(3.5)$ & $<0.001$ \\
Waist $(\mathrm{cm})$ & $95.7(8.4)$ & $106.7(8.5)$ & $<0.001$ \\
Waist-to-hip ratio & $0.95(0.06)$ & $1.01(0.07)$ & $<0.001$ \\
Systolic BP (mmHg) & $146.0(20.2)$ & $150.3(19.3)$ & $<0.001$ \\
Diastolic BP (mmHg) & $73.9(10.2)$ & $76.1(10.3)$ & $<0.001$ \\
Glucose (mmol/l) & $5.39(0.73)$ & $6.22(1.37)$ & $<0.001$ \\
TG (mmol/l) & $1.05(0.47)$ & $1.79(0.88)$ & $<0.001$ \\
HDL (mmol/l) & $1.50(0.35)$ & $1.20(0.30)$ & $<0.001$ \\
LDL (mmol/l) & $2.98(0.84)$ & $2.87(0.87)$ & 0.001 \\
IGF1 $(\mu \mathrm{g} / \mathrm{l})$ & $139.7(57.9)$ & $144.4(60.2)$ & 0.042 \\
IGFBP3 $(\mu \mathrm{g} / \mathrm{l})$ & $3791.3(856.8)$ & $3849.0(1001.4)$ & 0.105 \\
IGF1/lGFBP3 & $0.037(0.013)$ & $0.038(0.014)$ & 0.058 \\
IGFBP1 $(\mu \mathrm{g} / \mathrm{l})$ & $32.3(20.7)$ & $22.2(18.5)$ & $<0.001$ \\
\hline
\end{tabular}

quintiles of IGFBP3 (overall significance $P<0.001$ ). Increasing IGFBP1 was associated with reduced risk of metabolic syndrome with a dose-response gradient. For IGFBP1, with Q1 as the reference group, OR (95\% CI) for metabolic syndrome for Q2 was 0.56 (0.43-0.74, $\quad P<0.001) ; \quad Q 3, \quad 0.33 \quad(0.26-0.44$, $P<0.001) ; Q 4,0.22$ (0.17-0.30, $P<0.001)$; and $Q 5$, $0.12(0.09-0.17, P<0.001)$. There was a significant trend across quintiles of IGFBP1 (overall significance $P<0.001$ ). IGF1/IGFBP3 ratio was not associated with metabolic syndrome.

Inclusion of medical comorbidity (Charlson score) did not appreciably alter the results of the multivariate analysis. The manufacturer's absolute range of IGF1 values for 18 normal men $>60$ years of age is $118-314 \mu \mathrm{g} / \mathrm{l}$. Only 31 men had IGF1 values above the upper limit of this reference range, who might possibly have had undiagnosed acromegaly. Excluding these men from the analysis did not affect the results.

\section{Association of IGF1, IGFBP3, IGFBPI and IGF1/IGFBP3 ratio with individual components of the metabolic syndrome}

Relationships between IGF1, IGFBP3, IGFBP1 and the IGF1/IGFBP3 ratio with individual components of the metabolic syndrome are shown in Table 3. Higher IGF1 level was associated with triglyceride level $\geq 1.7 \mathrm{mmol} / \mathrm{l}$ and with the presence of hypertension. Lower IGFBP3 level was associated with waist circumference $>102 \mathrm{~cm}$ and HDL $<1.03 \mathrm{mmol} / \mathrm{l}$, while higher IGFBP3 was associated with glucose $\geq 5.6 \mathrm{mmol} / \mathrm{l}$, elevated triglycerides and hypertension. Lower IGFBP1 levels were associated with waist circumference, elevated glucose and triglyceride levels, and with lower HDL levels. The ratio of IGF1/IGFBP3 was associated only with lower HDL. 

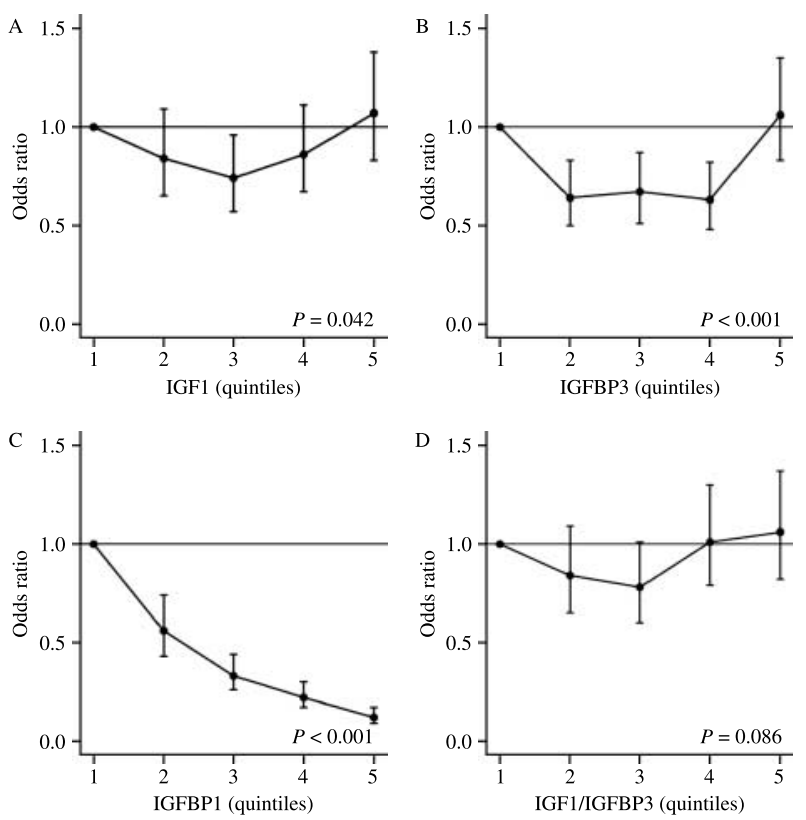

Figure 2 Associations of IGF1, IGFBP3, IGFBP1 and IGF1/IGFBP3 with metabolic syndrome in older men. Logistic regression analysis of metabolic syndrome on IGF1, IGFBP3, IGFBP1 and the ratio of IGF1/IGFBP3 modelled as quintiles and adjusted for age, smoking and alcohol use. Results are shown as odds ratios for the presence of metabolic syndrome in each quintile, and refer to effect estimates. Bars refer to $95 \%$ confidence intervals. Quintile 1 contained the lowest values. $P$ value is for test of overall significance.

\section{Discussion}

In this large cohort of community-dwelling older men, age-adjusted logistic regression analysis revealed a significant U-shaped association with men in the middle-range of the distributions of IGF1 and IGFBP3 having the lowest risk of metabolic syndrome. By contrast, a strong linear inverse relationship existed for IGFBP1 and metabolic syndrome, with men in the lowest quintile exhibiting an eightfold greater risk compared to men in the highest quintile of IGFBP1 values. The IGF1/IGFBP3 ratio was not associated with metabolic syndrome in our study.

These findings in older men aged $\geq 70$ years contrast with previously reported studies in younger and middleaged men $(18,25-27)$. In a report of 1463 younger men aged 20-49 years from the Third National Health and Nutrition Examination Survey (NHANES III), men in the lowest quartile of the IGF1/IGFBP3 ratio were three times more likely to meet the same definition of metabolic syndrome (18). A separate analysis based on NHANES III data including men aged 50 years and above found that metabolic syndrome was associated with lower levels of IGF1 and a reduced ratio of IGF1/IGFBP3 (25). In a sample of 359 European men aged 30-64 years, IGF1 levels correlated inversely with fasting glucose, and were associated with lipid and obesity/glucose factors in a principal component

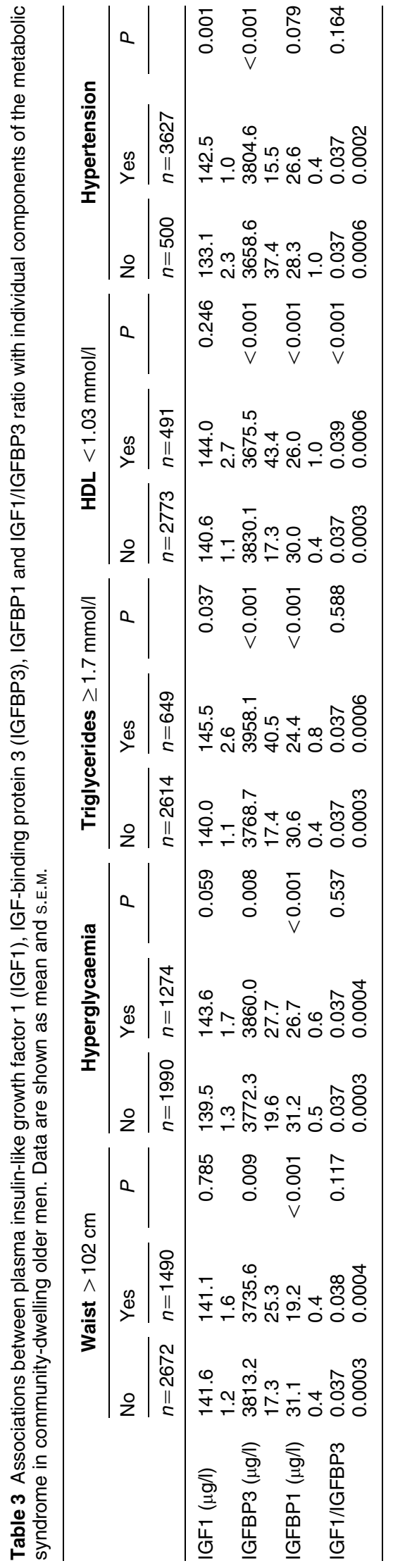

www.eje-online.org 
analysis (26). A study of 179 middle-aged Asian men (aged $39 \pm 8$ years) also identified the men in the lowest tertile of IGF1 as having increased frequency of metabolic syndrome (27). Therefore, one conclusion is that the association between IGF1 and IGFBP3 with metabolic syndrome differs in older compared with younger and middle-aged men. While lower IGF1 or IGFBP 3 is associated with a greater likelihood of having metabolic syndrome in men across the range of ages, in older men those with the highest values of IGF1 or IGFBP3 are also at risk.

Differences in associations between IGF 1 and IGFBP3 and individual cardiovascular risk factors could contribute to the relationship with metabolic syndrome. For example, a European study that included 200 men ranging in age from 18 to 80 years without pituitary and cardiovascular disease found that IGF1 levels in the low normal range were associated with hypertension and diabetes (28). Higher IGF1 levels were associated with insulin sensitivity in adults with normal or impaired glucose tolerance or diabetes (29), and with reduced odds of developing glucose intolerance or type 2 diabetes in middle-aged adults (30). Higher IGF1 levels have not been implicated previously as contributing to risk of metabolic syndrome. In addition, we found that a higher IGF1 level was associated with elevated triglyceride level and with the presence of hypertension. Therefore, the relationship between IGF1 and individual cardiovascular risk factors may differ in older compared with younger and middle-aged men. It has been postulated that IGF1 has direct actions in the vasculature, which may be detrimental (e.g. induction of smooth muscle proliferation) or beneficial (e.g. vasodilation and preservation of endothelial function; for review, see (31)). This would be in keeping with the concept that mid-range values for IGF1 are most favourable in terms of cardiovascular risk as reflected by association with metabolic syndrome.

Lower IGFBP3 level was associated with elevated waist circumference and reduced HDL level, while higher IGFBP3 was associated with impaired fasting glucose, elevated triglycerides and hypertension. Thus, in older men, lower and higher IGFBP 3 levels are differentially associated with individual components of the metabolic syndrome, which corresponds to men with IGFBP3 values in the lowest and highest quintiles having the greatest risk of metabolic syndrome.

Therefore, the U-shaped relationship for IGF1 and IGFBP 3 to risk of metabolic syndrome differs from that observed in most previously reported studies. Our cohort comprised men only, with a tight age range between 70 and 89 years rather than a spread across younger or middle-aged to older men. Furthermore, the large number of men in our study provided greater power to clarify associations between IGF1 and IGFBP3 with metabolic syndrome.

Men with higher IGFBP1 levels had lower OR for metabolic syndrome after adjusting for age. This is consistent with previous studies in men of varying ages in linking IGFBP1 levels with insulin sensitivity (19, $20,32,33)$. Thus, lower IGFBP1 levels were associated with impaired glucose tolerance in an ethnically diverse sample of 272 adults from Manchester (19) and with metabolic syndrome in 839 adults aged 40-65 years in the Cambridgeshire study (20). Another cross-sectional study found that lower IGFBP1 levels were associated with known cardiovascular risk factors in 273 adults aged 20-74 years (32). Our results are in keeping with a previous smaller study involving 331 Finnish men aged 70-89 years in which IGFBP1 levels correlated with insulin sensitivity (33). The inverse relationship between IGFBP1 and metabolic syndrome could be explained by its role as a marker of insulin sensitivity, as IGFBP1 correlates closely to whole-body and hepatic insulin sensitivity (34, 35). Thus, IGFBP1 represents an informative marker for metabolic syndrome in ageing men, with an eightfold reduction in the age-adjusted OR for metabolic syndrome for men in the highest quintile compared to those in the lowest quintile of values.

Unique features of this study are the size of the cohort and its focus on older men rather than on men across a range of ages. These men were community-dwelling and were not selected on the basis of an existing medical condition. We performed IGF1, IGFBP1 and IGFBP 3 assays on plasma aliquots that had been preserved at $-80^{\circ} \mathrm{C}$ from the time of specimen collection until assay. The assays used were robust for plasma or serum samples. In the multivariate analysis, we adjusted for a range of potential confounders, including age, smoking and alcohol use (36). Limitations of the study include the cross-sectional nature of the analysis which limits conclusions as to the direction of causality, and that we did not have the opportunity to collect serial blood samples to determine changes in hormone levels over time. The cohort comprised 4263 men who returned for assessment and blood sampling between 2001 and 2004, from an original sample of 12203 men screened in 1996-1999 (22). Therefore, a 'healthy survivor' effect is possible, and we cannot comment on associations in women. Furthermore, we did not attempt to measure 'free' IGF1 levels (5). A recently reported bioassay based on activation of the IGF1-specific kinase receptor may provide a means of assessing circulating IGF1 bioactivity (37), but this method is not in general use at present. Thus, we assayed total IGF1 as an accepted measure of IGF1 status.

The presence of metabolic syndrome is associated with greater risk of new onset diabetes and increased incidence of cardiovascular events $(38,39)$. Therefore, the observation that there is a U-shaped association between IGF1 and IGFBP3 levels with metabolic syndrome in older men may explain part of the variation in associations of IGF1 with cardiovascular outcomes reported in previous studies. For instance, lower total IGF1 levels were associated with increased 
mortality in a study of 633 men aged 51-98 years (9), and in a study of 1988 men aged 20-79 years (10). Low circulating IGF1 bioactivity predicted higher mortality in 374 men aged 73-94 years (37). However, lower IGF1 did not predict all-cause or cardiovascular mortality in the NHANES III study (14), and in a contrary result, high total IGF1 levels predicted increased all-cause mortality in a study of 642 adults aged 50-89 years (15). A U-shaped association may help to explain why other studies of men ranging from middle to older age have shown either lower IGF1 levels (6-10) or higher IGF1 levels $(12,13,15)$ to be predictive of poorer cardiovascular outcomes. Similarly, our findings could be relevant to studies that have correlated either higher IGFBP 3 levels $(6,7,12,13)$ or lower IGFBP 3 levels $(8,11)$ with increased cardiovascular risk or cardiovascular events.

Our results indicate that in older men, the IGF1/IGFBP3 ratio, either as a distinct measure or as a surrogate for 'free' IGF1, may not be an important predictor of metabolic health. As associations between IGF1 and IGFBP3 with metabolic syndrome were comparable, these data do not suggest any independent effect of IGFBP 3 distinct from its stoichiometric relationship with IGF1. It is possible that the link between IGF1 or IGFBP 3 and cardiovascular mortality might be mediated independently of the metabolic syndrome. Thus, reduced IGF1 may be a marker for pre-existing ill-health (for example, poor nutritional status), accounting for its association with mortality. Longitudinal follow-up of our cohort could potentially determine whether the U-shaped relationship between IGF1 and IGFBP3 with metabolic syndrome translates into a corresponding association with incident cardiovascular events in older men.

In our study and in other reports, higher IGFBP1 levels are associated with insulin sensitivity and favourable metabolic status. However, while Laughlin et al. found that lower IGFBP1 levels predicted mortality over 9-13 years of follow-up (9), another study in 335 men aged 70-89 years found no relationship between IGFBP1 and 5-year mortality (40), while a study of 622 men aged 65-84 years reported that high IGFBP1 levels were associated with increased 5-year total and cardiovascular mortality (41). In contrast, our crosssectional study supports the concept that reduced IGFBP1 levels might be associated with poorer cardiovascular outcomes, but additional prospective studies are needed to clarify this area.

The broader clinical utility of levels of IGF1 and its binding proteins also remains to be determined. One or more of them may eventually find their place as measures of the risk of developing significant cardiovascular or metabolic disease, but whether they play a causal role in such relationships and the prospects they offer for intervention if they do are not yet clear. Alternatively, levels of these species may actually be epiphenomena reflecting the state of underlying and directly causal pathophysiological processes, in which case whether or not their levels change when other interventions affect those processes may be the chief determinant of their clinical utility.

\section{Conclusions}

In our large study of older men, plasma IGF1 and its binding proteins 3 and 1 are differentially associated with metabolic syndrome. IGF1 and IGFBP 3 levels in the middle of the distribution were associated with lowest risk, while increasing IGFBP1 was associated with reduced risk. These results may help to account for the divergent associations between IGF1, IGFBP3 and IGFBP1 with cardiovascular outcomes reported in several previous studies. Additional research is needed to clarify the potential utility of these measures to stratify cardiovascular risk in ageing men.

\section{Declaration of interest}

The authors declare that there is no conflict of interest that could be perceived as prejudicing the impartiality of the research reported.

\section{Funding}

Hormone assays were funded by Project Grant 513823 from the National Health and Medical Research Council of Australia (NHMRC). The Health In Men Study was funded by NHMRC Project Grants 279408, 379600 and 403963. B B Yeap is recipient of a Clinical Investigator Award from the Sylvia and Charles Viertel Charitable Foundation, New South Wales, Australia. P E Norman is supported by NHMRC Practitioner Fellowship 458505.

\section{Acknowledgements}

The authors gratefully acknowledge Sylvia Johnson of DSL Australia for her specialist help in setting up the IGF1 and IGF-binding protein assays, and thank Seamus Duffy for excellent technical assistance. We thank the staff and management of Shenton Park Hospital for providing space in which to conduct study-related clinics. We especially thank all the men and staff who participated in the Western Australian Abdominal Aortic Aneurysm Program and the Health In Men Study.

\section{References}

1 Veldhuis JD. Aging and hormones of the hypothalamo-pituitary axis: gonadotropic axis in men and somatotropic axes in men and women. Ageing Research Reviews 20087 189-208.

2 van der Klaauw AA, Biermasz NR, Feskens EJM, Bos MB, Smit JWA, Roelfsema F, Corssmit EPM, Pijl H, Romijn JA \& Pereira AM. The prevalence of the metabolic syndrome is increased in patients with GH deficiency, irrespective of long-term substitution with recombinant human GH. European Journal of Endocrinology 2007156 455-462.

3 Hana V, Silha JV, Justova V, Lacinova Z, Stepan JJ \& Murphy LJ. The effects of GH replacement in adult GH-deficient patients: changes in body composition without concomitant changes in the adipokines and insulin resistance. Clinical Endocrinology 200460 $442-450$. 
4 Colao A, Di Somma C, Spiezia S, Savastano S, Rota F, Savanelli MC \& Lombardi G. Growth hormone treatment on atherosclerosis: results of a 5-year open, prospective, controlled study in male patients with severe growth hormone deficiency. Journal of Clinical Endocrinology and Metabolism 200893 3416-3424.

5 Janssen JAMJL, Stolk RP, Pols HAP, Grobbee DE \& Lamberts SWJ. Serum total IGF1, free IGF1, and IGFBP-1 levels in an elderly population. Relation to cardiovascular risk factors and disease. Arteriosclerosis, Thrombosis, and Vascular Biology $1998 \mathbf{1 8}$ 277-282.

6 Colangelo LA, Liu K \& Gapstur SM. Insulin-like growth factor-1, insulin-like growth factor binding protein-3, and cardiovascular disease risk factors in young black men and white men. The CARDIA male hormone study. American Journal of Epidemiology $2004160750-757$.

7 Juul A, Scheike T, Davidsen M, Gyllenborg J \& Jorgensen T. Low serum insulin-like growth factor I is associated with increased risk of ischemic heart disease. A population-based case-control study. Circulation 2002106 939-944.

8 Johnsen SP, Hundborg HH, Sorensen HT, Orskov H, Tjonneland A, Overvad K \& Jorgensen JO. Insulin-like growth factor (IGF) I, -II and IGF binding protein-3 and risk of ischemic stroke. Journal of Clinical Endocrinology and Metabolism $2005905937-5941$.

9 Laughlin GA, Barrett-Connor E, Criqui MH \& Kritz-Silverstein D. The prospective association of serum insulin-like growth factor I (IGF1) and IGF-binding protein-1 levels with all cause and cardiovascular disease mortality in older adults: the Rancho Bernardo Study. Journal of Clinical Endocrinology and Metabolism 200489 114-120.

10 Friedrich N, Haring R, Nauck M, Ludemann J, Rosskopf D, SpilckeLiss E, Felix SB, Dorr M, Brabant G, Volzke H \& Wallaschofski H. Mortality and serum insulin-like growth factor (IGF)-I and IGF binding protein 3 concentrations. Journal of Clinical Endocrinology and Metabolism 200994 1732-1739.

11 Kaplan RC, McGinn AP, Pollak MN, Kuller LH, Strickler HD, Rohan TE, Cappola AR, Xue X \& Psaty BM. Association of total insulin-like growth factor-I, insulin-like growth factor binding protein-1 (IGFBP-1), and IGFBP-3 levels with incident coronary events and ischemic stroke. Journal of Clinical Endocrinology and Metabolism 200792 1319-1325.

12 Fischer F, Schulte H, Mohan S, Tataru MC, Kohler E, Assmann G \& von Eckardstein A. Associations of insulin-like growth factors, insulin-like growth factor binding proteins and acid-labile subunit with coronary heart disease. Clinical Endocrinology $2004 \mathbf{6 1}$ 595-602.

13 Kawachi S, Takeda N, Sasaki A, Kokubo Y, Takami K, Sarui H, Hayashi M, Yamakita N \& Yasuda K. Circulating insulin-like growth factor-1 and insulin-like growth factor binding protein-3 are associated with early carotid atherosclerosis. Arteriosclerosis, Thrombosis, and Vascular Biology 200525 617-621.

14 Saydah S, Graubard B, Ballard-Barbash R \& Berrigan D. Insulinlike growth factors and subsequent risk of mortality in the United States. American Journal of Epidemiology 2007166 518-526.

15 Andreassen M, Raymond I, Kistorp C, Hildebrandt P, Faber J \& Kristensen LO. IGF1 as a predictor of all cause mortality and cardiovascular disease in an elderly population. European Journal of Endocrinology $2009 \mathbf{1 6 0}$ 25-31.

16 Rosen CJ. Serum insulin-like growth factors and insulin-like growth factor-binding proteins: clinical implications. Clinical Chemistry $1999451384-1390$.

17 Firth SM \& Baxter RC. Cellular actions of the insulin-like growth factor binding proteins. Endocrine Reviews 200223 824-854.

18 Sierra-Johnson J, Romero-Corral A, Somers VK, Lopez-Jimenez F, Malarstig A, Brismar K, Hamsten A, Fisher RM \& Hellenius M-L. IGF1/IGFBP-3 ratio: a mechanistic insight into the metabolic syndrome. Clinical Science 2009116 507-512.

19 Heald AH, Cruickshank JK, Riste LK, Cade JE, Anderson S, Greenhalgh A, Sampayo J, Taylor W, Fraser W, White A \& Gibson JM. Close relation of fasting insulin-like growth factor binding protein-1 (IGFBP-1) with glucose tolerance and cardiovascular risk in two populations. Diabetologia 200144 333-339.
20 Kaushal K, Heald AH, Siddals KW, Sandhu MS, Dunger DB, Gibson JM \& Wareham NJ. The impact of abnormalities in the IGF and inflammatory systems on the metabolic syndrome. Diabetes Care 200427 2682-2688.

21 Leinonen ES, Salonen JT, Salonen RM, Koistinen RA, Leinonen PJ, Sarna SS \& Taskinen MR. Reduced IGFBP-1 is associated with thickening of the carotid wall in type 2 diabetes. Diabetes Care 200225 1807-1812.

22 Norman PE, Flicker L, Almeida OP, Hankey GJ, Hyde Z \& Jamrozik K. Cohort Profile: The Health In Men Study (HIMS). International Journal of Epidemiology 200938 48-52.

23 Charlson ME, Pompei P, Ales KL \& MacKenzie CR. A new method of classifying prognostic comorbidity in longitudinal studies: development and validation. Journal of Chronic Diseases $1987 \mathbf{4 0}$ 373-383.

24 Alberti KGMM, Zimmet P \& Shaw J. Metabolic syndrome - a new world-wide definition. A consensus statement from the International Diabetes Federation. Diabetic Medicine 200623 469-480.

25 Saydah S, Ballard-Barbash R \& Potischman N. Association of metabolic syndrome with insulin-like growth factors among adults in the US. Cancer Causes \& Control, 2009. DOI: $10.1007 / \mathrm{s} 10522-009-9351-\mathrm{x}$.

26 Maison P, Balkau B, Souberbielle JC, Cunin P, Vol S, MacquinMavier I \& Eschwege E. Evidence for distinct effects of $\mathrm{GH}$ and IGF1 in the metabolic syndrome. Diabetic Medicine 200724 1012-1018.

27 Tong PCY, Ho C-S, Yeung VTF, Ng MCY, So W-Y, Ozaki R, Ko GTC, Ma RCW, Poon E, Chan NN, Lam CWK \& Chan JCN. Association of testosterone, insulin-like growth factor-I, and C-reactive protein with metabolic syndrome in Chinese middle-aged men with a family history of type 2 diabetes. Journal of Clinical Endocrinology and Metabolism $2005906418-6423$.

28 Colao A, Di Somma C, Cascella T, Pivonello R, Vitale G, Grasso LFS, Lombardi G \& Savastano S. Relationships between serum IGF1 levels, blood pressure, and glucose tolerance: an observational, exploratory study in 404 subjects. European Journal of Endocrinology 2008159 389-397.

29 Sesti G, Sciacqua A, Cardellini M, Marini MA, Maio R, Vatrano M, Succurro E, Lauro R, Federici M \& Perticone F. Plasma concentration of IGF1 is independently associated with insulin sensitivity in subjects with different degrees of glucose tolerance. Diabetes Care 200528 132-137.

30 Sandhu MS, Heald AH, Gibson JM, Cruickshank JK, Dunger DB \& Wareham NJ. Circulating concentrations of insulin-like growth factor-I and development of glucose intolerance: a prospective observational study. Lancet 2002359 1740-1745.

31 Conti E, Carrozza C, Capoluongo E, Volpe M, Crea F, Zuppi C \& Andreotti F. Insulin-like growth factor-1 as a vascular protective factor. Circulation $20041102260-2265$.

32 Unden A-L, Elofsson S \& Brismar K. Gender differences in the relation of insulin-like growth factor binding protein-1 to cardiovascular risk factors: a population based study. Clinical Endocrinology 200563 94-102.

33 Harrela M, Koistinen R, Tuomilehto J, Nissinen A \& Seppala M. Low serum insulin-like growth factor-binding protein-1 is associated with an unfavourable cardiovascular risk profile in elderly men. Annals of Medicine 200032 424-428.

34 Maddux BA, Chan A, De Filippis EA, Mandarino LJ \& Goldfine ID. IGF-binding protein-1 levels are related to insulin-mediated glucose disposal and are a potential serum marker of insulin resistance. Diabetes Care 200629 1535-1537.

35 Kotronen A, Lewitt M, Hall K, Brismar K \& Yki-Jarvinen H. Insulin-like growth factor binding protein 1 as a novel specific marker of hepatic insulin sensitivity. Journal of Clinical Endocrinology and Metabolism 200893 4867-4872.

36 Goodman-Gruen D \& Barrett-Connor E. Epidemiology of insulinlike growth factor-I in elderly men and women. American Journal of Epidemiology $1997 \mathbf{1 4 5}$ 970-976.

37 Brugts MP, van den Beld AW, Hofland LJ, van der Wansem K, van Koetsveld PM, Frystyk J, Lamberts SWJ \& Janssen JAMJL. 
Low circulating insulin-like growth factor I bioactivity in elderly men is associated with increased mortality. Journal of Clinical Endocrinology and Metabolism 200893 2515-2522.

38 Wilson PW, D'Agostino RB, Parise H, Sullivan L \& Meigs JB. Metabolic syndrome as a precursor of cardiovascular disease and type 2 diabetes mellitus. Circulation 2005112 3066-3072.

39 Cornier M-A, Dabelea D, Hernandez TL, Lindstrom RC, Steig AJ, Stob NR, Van Pelt RE, Wang H \& Eckel RH. The metabolic syndrome. Endocrine Reviews 200829 777-822.

40 Kalme T, Seppala M, Qiao Q, Koistinen R, Nissinen A, Harrela M, Loukovaara M, Leinonen M, Leinonen P \& Tuomilehto J. Sex hormone-binding globulin and insulin-like growth factor-binding protein-1 as indicators of metabolic syndrome, cardiovascular risk, and mortality in elderly men. Journal of Clinical Endocrinology and Metabolism 200590 1550-1556.

41 Harrela M, Qiao Q, Koistinen R, Tuomilehto J, Nissinen A, Seppala M \& Leinonen P. High serum insulin-like growth factor binding protein-1 is associated with increased cardiovascular mortality in elderly men. Hormone and Metabolic Research 200234 144-149.

Received 5 November 2009

Accepted 13 November 2009 